\title{
Research of the model of the agricultural products service supply chain based on intent platform
}

\author{
Yan Cui ${ }^{1, \text { a }}$, Zi Xiang Zhang ${ }^{2, b}$ \\ ${ }^{1}$ College of Mechanical and Electrical Engineering, Henan Agricultural University, Zhengzhou \\ 450002, China \\ ${ }^{2}$ College of Mechanical and Electrical Engineering, Henan Agricultural University, Zhengzhou \\ 450002, China \\ aemail: cuiyan6198@163.com, ${ }^{\mathrm{b} e m a i l}: 18137273604 @ 163 . c o m$
}

Keywords: Internet Technology; Agricultural Products; Supply Chain; New Model

\begin{abstract}
Through the increasing development of Internet technology, computer walks in every families, the traditional consumption concept and patterns also changed, based on the consumption patterns of the network platform is gradually accepted and recognized. Therefore, the corresponding logistics concept also changed. Similarly, with the improvement of people's consumption level, the requirement of agricultural products also gradually improve, so the corresponding traditional agricultural products circulation faces the challenge, urgent need to find a new breakthrough. In this paper, starting from the supply chain of agricultural products and the new model will be put forward, which is based on the present situation.
\end{abstract}

\section{Introduction}

In recent years, with suspension economic growth, the income level of resident is improving constantly, China's urban residents' food consumption structure is quietly changing-along with the percentages of traditional grain products in the food consumption decline while the fresh food represented by fresh fruits, vegetables and meat prevail [1].At the same time, with the speeding up of urbanization, the population of China's urban residents is also increasing rapidly. Demand for the consumption of fresh agricultural products in China's country will definitely maintain a rapid growth in the future ten years or even longer period of time, in line with the effects of both the change of food consumption structure and the growth of urban residents. For this reason, based on various types of e-commerce platform of the agricultural products logistics industry will have an important opportunity for development.

Agricultural products logistics fundamental way that the flow of information, as well as the safety of products, it will ensure the flow of schindler resistance, but also to avoid excessive waste blind cultivation and sales of nowhere, so make internet-based platform for agricultural products logistics service supply chain not only help farmers increase income, but also to ensure the supply and freshness businesses, achieve win-win goal.

\section{Agricultural Products Service Supply Chain}

Service supply chain is one of the new trend of the study on supply chain [2], while the logistics service supply chain is one of the service supply chain. LSSC is LSI-led, was composed of FLSP, LSI and manufacturers new service supply chain, though providing flexible logistics services to meet the demand of product supply chain logistics operation [3-5].

Modern agricultural represents high standards in agricultural products logistics, both easy, quick and send low cost of agricultural products to sale terminal market, thus agricultural products logistics service supply chain has become a hot research field at present. But the scope of its research is mainly concentrated in the agricultural products logistics resources integration and sharing, architecture of the model and optimization, the ability of logistics service supply chain distribution of coordination and cooperation coordination etc. [6].In today's China, however, with 
the popularity of computer, the rise of Alibaba, Jindong, just-in-time, and so on, such as people more and more interested in this kind of new consumption patterns, and explore a set of platform about agricultural products online distribution model is more important, it is play an important guiding role in solve difficulty selling and buying agricultural products and blind cultivation and also for reducing the intermediate circulation, increasing farmers income.

\section{Discussing Several Kinds of Agricultural Products Logistics Supply Chain Model Based on the Age of the Internet}

Now several modes of China's agricultural products supply chain are:1) dominated by the wholesale of agricultural products supply chain model; 2) dominated by the chain operation of agricultural products supply chain model; 3) dominated by the processing of agricultural products supply chain model; 4) dominated by the third party logistics company's supply chain model; 5) agricultural products leading enterprises as the leading model of supply chain; 6) the supply and marketing cooperatives or farmers organization of supply chain model [7]. Throughout the agricultural product circulation pattern, it is easy to find, the current agricultural product circulation pattern of the main problems are: 1) inadequate control comprehensive; 2) the lack of timely information feedback; 3) degree of integration needs to be strengthened [8].

Based on the mode of the agricultural products supply chain, combined with the basic model of logistics service supply chain, relying on the current Internet technology, the reference of the existing electric business logistics mode, combined with the characteristics of agricultural products circulation and uniqueness, put forward several kinds of new agricultural products logistics service supply chain model.

\section{Farmers Self-marketing Model}

Agricultural products logistics in rural areas still mainly depends on farmers in the form of self-marketing in China, due to the weak consciousness and the lack of information of the market, planting varieties and quantity in a disconnected with the market, in the form of completely rely on past experience, appear easily price ups and downs phenomenon. Selling form mostly depends on the countryside market, open selling both contributed to aggravation the transportation cost, and because of lots of different product which caused the sales is different, the difference caused by the different freshness, finally selling the residual waste, farmers often have to bear these losses themselves, indirectly lead to lifting the unit price of vegetables [9].

Thus the first model in this paper is based on the self-employed farmers grow or possess small greenhouses, integrated logistics service provider network platform to provide specialized information including breed, number of acres and associated pricing information for farmers.

Relying on this platform, the types of vegetables the day of production for farmers, quantity and sale price hanging on the page, as shown in Figure 1. Cook so that farmers shouldn't pull all the vegetables sell on the bazaar, saving the cost and guarantee the freshness of vegetables, on the other hand consumers who near from the farmer can choose directly to the farmers here procurement, mode of operation with the maturity, trust buyers and sellers accumulated to a certain extent, you can launch an online ordering system and short distance distribution business.

Based on the same day the order quantity and sales, farmers can reasonably control the number of outputs and output ratio of their own vegetables, and to avoid unnecessary losses and waste.

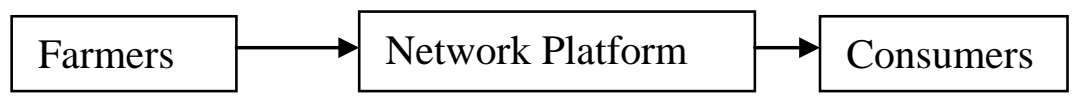

Fig.1. Farmers self-marketing model

With the improvement of living standards, more rural people are more like city people using the internet help. Such as online procurement, the lack of supermarkets and other convenience stores, more and more young people begin to shop online, saving time and money. Some cultivation knowledge and skills can be learned by the network. As more and more rural migrant workers as 
well as the normalization of China's urbanization progress, farmers' consumption, shopping perspective will slowly turn to e-commerce market. No doubt, the future of rural e-commerce market will nurture great opportunity and vitality.

Therefore, this kind of mode if mature operation, will produce the centralization of the rural market of agricultural products sales and professional development, also for the promotion and development of villages and towns now logistics industry also has a great role in promoting, the author thinks it can greatly promote the development of rural agricultural products, improve the living standards of farmers, bring the villages and towns people's life more convenience.

\section{Wholesale Market Model}

The wholesale still the main channel for agricultural products here and now, wholesale market collected vegetables and other agricultural products from farmers, and then to the various district near the vegetable market, various restaurants, but in the process of circulation of concrete, because of the uncertainty of the supply and demand, and lead to a lot of waste as well as the price of ups and downs, the situation of the wholesale market in China at present stage is: mainly dominated by wholesale market, operators are mostly scattered peasants, small management scale, economic strength is weak, the lack of specialized knowledge of management, and do not have the legal person status, mostly on business there are serious spontaneity and blindness. Wholesale market layout is unreasonable, the lack of unified planning; lagging information net construction, the detention of information diffusion channel; means of exchange lag behind; wholesale market legal construction lags behind [10].

Based on this situation, we put forward the second mode, the network platform which based logistics service chain, as shown in Figure 2. Through this platform, forming the circulation and exchange of information between the retailers, wholesale market and farmers. Such wholesale various retailers can rely on this platform to their basic daily needs of the reaction in the form of orders, including the need for variety and quality requirements. Then relying on the wholesale market demand orders, develop their own procurement plans, not only ensure the demand and reduce inventory, but also avoid unnecessary waste, so that the overall market demand for vegetable prices stabilize.

We all know that agricultural products into commodities after its freshness occupy a very important part in the share price, so high during storage warehouse requirements, so that effectively reduce inventory levels will bring great benefits, thus authors believe that this pattern will be up and running, then reduce inventory, reduce play a role on the circulation of agricultural products, and thus the construction and development of specialized wholesale markets run play an important role.

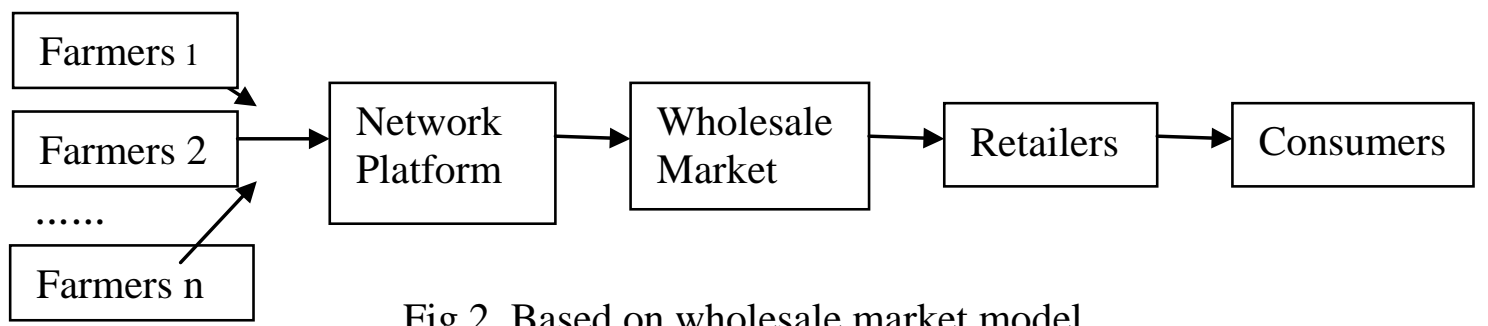

Fig.2. Based on wholesale market model

\section{The Model Based on Farmer-supermarket Docking}

Farmer-supermarket docking is a fresh agricultural products "supermarket + base" flow-through mode, large supermarket chains and agricultural cooperatives directly to docking, the establishment of agricultural direct procurement base, and major supermarket chains and fresh agricultural produce of farmers or cooperatives and marketing docking [11]. This flow pattern on the one hand for the agricultural products provides a good platform for the sale, by means of high-quality agricultural supermarket sound distribution system, market sensitive antennae, with the fastest speed in every household, solve the problem of difficulty in selling fresh produce; on the other hand 
to achieve the quality of agricultural products from farm to table the whole process of control, improve the quality of agricultural products the safest level of integrated production and marketing chain constructed under market economy conditions, achieve merchants, farmers, consumers win.

Based farmer-supermarket docking mode, using the idea of supply chain logistics services, as shown in Figure 3. Farm to extend the scope of the fruits and vegetables, as we all know, the fruits of agricultural products as the distance from the origin of the increase, the corresponding costs will increase, thus bringing the price of expensive, contemplated herein, the logistics service network platform based on the supply chain, so that each place of origin can put their characteristics fruit, specialty, acreage and yield linked to the Web page, the respective supermarkets can select their own investigation on the basis of the actual information fruit suppliers, through the network to complete the order, both for goods from the origin to the supermarket direct resistance, but also conducive to the professional development of the logistics level, it can save costs and avoid unnecessary waste, reduce fruit in a non-origin prices.

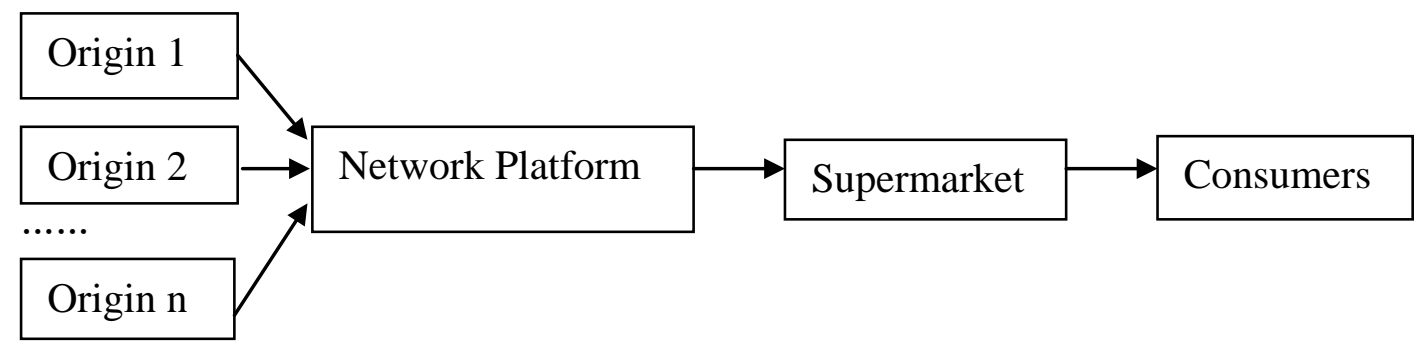

Fig.3. The model based on farmer-supermarket docking

The purpose of this model is proposed to reduce the cost of supermarket purchases, with this platform, a supermarket manager who can filter through internet, in line with their requirements and then determine the origin, finalize procurement program through field visits, saving time and costs. At the same time, since the circulation of information, and can speed up the development and improve the traffic situation in the origin of the logistics industry itself. Thus boosting economic development, improvement of living standards.

\section{Case Analysis}

Since 2010the "Suichang model" is in a typical case of the electricity suppliers to promote rural economic development, improve the quality of life of farmers.

Suichang County, Lishui City, Zhejiang Province, is a typical mountainous areas and old revolutionary base areas, mountainous area accounts for the county area of $88.83 \%$, Suichang rich in mineral resources, covering more than 30 kinds of gold, silver, copper, zinc and the like. Special agricultural products are bamboo charcoal, bamboo shoots, bamboo vinegar, camellia oil, mountain vegetables, fruits, etc. And has a wealth of mountain tourism resources.

The two major characteristics of the Suichang model: one is the electricity supplier originally scattered individuals, farmers, agricultural cooperatives, agricultural products processing enterprises, logistics companies to effectively integrate the overall shape of a complementary resources and service linkage; Suichang Association of network operators and then network company is another feature of the development of Suichang.

Through the survey found that the total sales of electronic commerce in Suichang, the characteristics of agricultural products and processed agricultural products sales accounted for more than 50\%. 2013 online sales of mountain agricultural products and processed products sales of 130 million yuan, accounting for 1.53\% of GDP in 2013 the county. Thus led to the production and sale of the 76 agricultural cooperatives, professional farmers. One of the more prominent: Chrysanthemum meters Cooperatives -talented chrysanthemum rice, Yufeng bamboo industry etc. Its online sales accounted for $45 \%, 62 \%$ of their total sales respectively.

In 2010 nodes, e-commerce to accelerate the development of the 3-year period, Suichang transportation, warehousing postal industry output increased by 243 million yuan, the growth rate reached $327.10 \%$. In traditional industries, due to the promotion of electronic commerce, the 2013 
Suichang traditional roast potato industry and chrysanthemum Mega industrial growth rate reached $20 \%$ and $19 \%$ respectively.

\section{Conclusion}

Research on Agricultural Products Logistics service supply chain is still in its infancy, but the study of the supply chain has reached a very advanced stage, combined with produce its own uniqueness and complexity of the transport of agricultural products, agricultural products logistics bound to the professional level of development, relying on in agricultural Products Logistics service Supply Chain will become a necessity.

2008 to 2013 five years, the Internet penetration rate of urban residents increased from $35.9 \%$ to $62 \%$, an increase of 26 percentage points; and the Internet penetration rate of rural residents was only $27.5 \%$, compared with the rate of urban residents, there is much room for development. In the future, the mobile network will be an important factor in the growth of rural Internet users. Currently mobile communication users $30 \%$ is rural users, rural mobile phone penetration rate is only $20 \%$, but from the recent 2 years, the new user structure, rural users have accounted for the new user's 50\%-70\%. Expected in the next 2-3 years, $60 \%$ of new users from the countryside and $40 \%$ from the city. August 2013, the State Council issued the broadband China strategy and implementation plan, stressed the strengthening of strategic guidance and system deployment, and promote the rapid and healthy development of China's broadband infrastructure, increase fiber to households, rural broadband access to rural areas, public service agencies broadband access. Can be seen, with the continued strengthening of infrastructure construction, rural infrastructure is no longer a barrier to restrict the development of the Internet, the number of future rural people using the Internet will be further enhanced.

With the advent of the information age, the impact of the consumption of electricity providers, people's consumption patterns of diversification, the network model will become a trend in agricultural product logistics service supply chain development, on agricultural logistics network platform construction, and network-based models Construction proceeds platform will also become the focus of research.

\section{References}

[1] Zhongzhen. The research of China's fresh agricultural products e-commerce development status of cold chain home delivery [J].Management Observer, vol. 2, pp. 84-86, 2015.

[2] Liuweihua, Jijianhua. Service supply chain: The new trend of supply chain studies China society of logistics[C]. The academic frontier report of China logistics 2006-2007. Beijing: China Logistics Publishing house, 2006, pp. 1-9.

[3] Ellram LM, Tate W L, Billington C. Understanding and managing the service supply chain [J].Journal of Supply Chain Management, vol. 4, pp. 17, 2004

[4] Liuweihua, Jijianhua, Baoxing. The levels ability to collaboration of logistics service supply chain [J]. Journal of Wuhan University of Technology, vol. 2, pp.149, 2008.

[5] Tianyu. The supplier selection in building of logistics service supply chain [J]. Systems Engineering Theory and Practice, vol. 5, pp. 49, 2003.

[6] Linxiaowei, Shuhui, Jiangminglin. Allocation of interests postal service supply chain of agricultural products logistics [J]. Journal of Qiqihar University, vol. 6, 2013.

[7] Pulingling. Comparative analysis of agricultural supply chain model [J]. Industrial and Science Tribune, vol. 5, 2015.

[8] Cuiyunpei. Agricultural supply chain analysis [J]. Market Research, 2013.

[9] Yuxiaoyan, Huangliping. China's logistics operation mode of agricultural research in supply 
chain [J]. Logistics Technology, vol. 11, pp. 51-52, 2004.

[10] Huangguihong, Raozhiwei. Integration of supply chain integration of agricultural product logistics [J]. Chinese Circulation Economy, vol. 2, pp. 29-32, 2011.

[11] Chenfang. Changes in procurement of agricultural products from the farm to see [J]. Market Modernization, vol. 29, pp. 1-3, 2009. 